\title{
Application of design of experiment to a FCAW process
}

\author{
Piotr Kordas ${ }^{1, *}$, Robert Bęczkowski ${ }^{2}$, Marek Gucwa ${ }^{1}$, and Jerzy Winczek ${ }^{1}$ \\ ${ }^{1}$ Institute of Mechanical Technology, Welding Department, Czestochowa University of Technology, \\ Czestochowa, Poland \\ ${ }^{2}$ H. Cegielski-Poznań S.A, Poznań, Poland
}

\begin{abstract}
This work presents the results of research on the anti-abrasion surfacing welds designated to operate under wear conditions. The main purpose of the work was to produce single-layer surface welds by means of semi-automatic hard-facing/surface welding with the use of filler material containing carbide precipitate and with the use of $10 \mathrm{~mm}$ - and $20 \mathrm{~mm}$ - wide beads. The samples were subject to visual and penetrant testing and to destructive testing in the form of macro and micro metallographic testing, hardness testing and bend testing with a view to determine the effect which thebeads of various widths have on the analyzed factors.
\end{abstract}

Keywords: hardfacing, cored wire, wear, structure, DOE

\section{Introduction}

Welding, metallurgy and advances in material science ensure the possibility of using more sophisticated metal materials that can move the working parameters higher and higher and increase the life of machines and equipment. To take advantage of the properties of these materials, consider the problem of wear at the design stage with the production and operation of machines. The most effective way to counteract consumption is to carry out work on the welding technology of surface materials with special properties. One such method is to prevent deposition, used for protection of the conveyor belts sides or loading plates administrator used in the mining industry [1-3].

In order to effectively improve the durability of metal-working machinery against abrasive wear, the following methods are used: preventive welding of surfaces or surfaces of technological welding materials allowing surface welds with high abrasion resistance. The surfacing welds include primary carbides with a targeted hard-phase distribution; or plates with a distinctive bead of the surfacing, which improves erosion resistance, that contain metallographic structural phases with a hardness of 1500 to $3000 \mathrm{HV} 10$ in the gaining surface layers. This depends to a large extent on the applied technological parameters of the production process that is the subject of this analysis [4-7].

Regardless of the opportunities offered by modern materials that improve surface properties, the wear and tear of parts is a fact and results it exploitation costs. From an

\footnotetext{
*Corresponding author: pkordas@wimii.pcz.pl

Reviewers: Czestaw Kundera, Dominik Wilczyński
} 
economic perspective, it is most advantageous to eliminate a friction couple of the device. It is possible to transport loose materials with all types of chutes, troughs, belt-driven tables, where grids are used to hold the material. As a result, a buffering layer is formed, and the friction couple consists of transported and poured material together with the material kept on the grids, thus making a perfect friction couple [1].

Adaptation of modern surface layer materials cannot assure that the resulting layers will without free of welding imperfections. That is describe in the norm ISO 6520. This standard contains classification of welding imperfections and divides it into 6 groups: cracks, cavities, solid inclusions, lack of fusion and penetration, imperfection shape and dimensions and miscellaneous imperfections. It also shows the welding imperfection symbol according to the following scheme: ISO 6520-1-no, where the designation number is the mark of imperfections [7-10]. In this case, the identification of imperfections at the permissible level can be determined in accordance with norm ISO 5817. Where three allowed levels can be found: from the highest $\mathrm{B}$, through the medium $\mathrm{C}$, to the lowest $\mathrm{D}$ [11].

The important issue in welding protect surface technologies is the correct determination of parameters affecting the quality and properties of the cladding surface. Changes of settings of the parameters give us the chance to gain deposit layers of a different microstructure, hardness and surface without defect [7, 12-15].

Welding technologies can be used both to build new layers as well as to rebuild the surface after wear in various industry sectors. It is possible to rebuild surfaces in terms of the properties of the base material and to improve the properties of the contact layer. Welding technologies allow for the construction of layers from small thicknesses, and with the use of multi-run technology where the thickness of the layer is not limited.

The hardnesses obtained in the manufacture of hardcoat layers depend on the materials used and the applied surfacing techniques. Adding hard particles carbides to the core is especially possible in the core. Determining material durability on wear is determined by two factors: hardness and structure [1, 10, 12-20].

Determining the degree of influence of a given input parameter on the final result with a large number of simultaneously acting parameters is troublesome and time consuming. Developing a research plan minimizes the necessary number of experiments that can produce credible results. Such opportunities provide experience planning based on statistical programs that optimize the number of experiments and help in the statistical development of the results obtained. The $2 \mathrm{k}$ plan are readily used for this purpose [2].

\section{Experimental Procedure}

The material used for surface welding tests was base material of type S235JR, $10 \mathrm{~mm}$ thick, which was covered with a surfacing weld by application of the MAG semi-automatic process. The liquid weld pool was shielded by the M21 gas mixture and a $1.2 \mathrm{~mm}$ cored wire. The applied wire allows to obtain in the surface layer with the surfacing weld hardness of 500 $600 \mathrm{HV} 10$. The surface welding process flow is presented in Fig. 1. The process was conducted with the use of a direct current source with the welding current in the range of 210-280 A with positive polarity. The test was conducted in the flat position [4].

The $2 \mathrm{k}$ plan has been applied in the context of the influence of technological parameters on the obtainable hard-ness of surfacing clad surface layer [10]. Variable parameters in this experiment:

- the distance between the contact tip and the tip of the electrode $L_{e}$ [mm], range of variation (20-30),

- current intensity $I[\mathrm{~A}]$, range of variation (213-277),

- welding velocity $\mathrm{V}_{\mathrm{s}}[\mathrm{cm} / \mathrm{min}]$, range of variation $(5,11)$. 
Knowledge of the ranges of variability of technological parameters allows to determine the central value and unit of variation for each parameter $(1,2)$

$$
\begin{gathered}
x_{i 0}=\frac{x_{i \max }+x_{i \min }}{2} \\
\Delta x_{i}=\frac{x_{i \max }-x_{i \min }}{2}
\end{gathered}
$$

whereby:

$-i$ - variable number,

- $x_{\text {imax }}$ - maximum value $i$-this input factor in variable range,

- $x_{\text {imin }}$ - minimum value $i$-this input factor in variable range.

The $2 \mathrm{k}$ plan based on the planning matrix for the experiment used $(\mathrm{N}=8)$ presented in the Table 1.

Table 1. Experiment plan $2^{\mathrm{k}}$

\begin{tabular}{ccccc}
\hline $\mathbf{N}$ & $\boldsymbol{L}_{\boldsymbol{e}}[\mathbf{m m}]$ & $\boldsymbol{I}[\mathbf{A}]$ & $\mathbf{V}_{\mathbf{s}}[\mathbf{c m} / \mathbf{m i n}]$ & $\boldsymbol{y}^{\cdot}$ \\
\hline 1 & 20 & 213 & 5 & yi1 \\
2 & 30 & 213 & 5 & yi2 \\
3 & 20 & 277 & 5 & yi3 \\
4 & 30 & 277 & 5 & yi4 \\
5 & 20 & 213 & 11 & yi5 \\
6 & 30 & 213 & 11 & yi6 \\
7 & 20 & 277 & 11 & yi7 \\
8 & 30 & 277 & 11 & yi8 \\
\hline
\end{tabular}

The matrix experiment $X$ is received in this way:

$$
X=\left[\begin{array}{cccc}
1 & 20 & 213 & 5 \\
1 & 30 & 213 & 5 \\
1 & 20 & 277 & 5 \\
1 & 30 & 277 & 5 \\
1 & 20 & 213 & 11 \\
1 & 30 & 213 & 11 \\
1 & 20 & 277 & 11 \\
1 & 30 & 277 & 11
\end{array}\right]
$$

Then changed natural variable for encoded variable $x_{i}{ }_{i}$ using formula (3):

$$
x_{i}^{\cdot}=\frac{x_{i}-x_{i 0}}{\Delta x_{i}}
$$

The matrix experiment after encoded variable ('-1' means low level of each factor and ' +1 ' means high level of each factor):

$$
X=\left[\begin{array}{llll}
1 & -1 & -1 & -1 \\
1 & +1 & -1 & -1 \\
1 & -1 & +1 & -1 \\
1 & +1 & +1 & -1 \\
1 & -1 & -1 & +1 \\
1 & +1 & -1 & +1 \\
1 & -1 & +1 & +1 \\
1 & +1 & +1 & +1
\end{array}\right]
$$

Then the matrix of regression coefficients is built in this way: 


$$
\begin{aligned}
& B=\left(X^{T} X\right)^{-1} X^{T} Y= \\
& {\left[\begin{array}{cccc}
\frac{1}{8} & 0 & 0 & 0 \\
0 & \frac{1}{8} & 0 & 0 \\
0 & 0 & \frac{1}{8} & 0 \\
0 & 0 & 0 & \frac{1}{8}
\end{array}\right] \times\left[\begin{array}{cccccccc}
1 & 1 & 1 & 1 & 1 & 1 & 1 & 1 \\
-1 & +1 & -1 & +1 & -1 & +1 & -1 & +1 \\
-1 & -1 & +1 & +1 & -1 & -1 & +1 & +1 \\
-1 & -1 & -1 & -1 & +1 & +1 & +1 & +1
\end{array}\right] \times\left[\begin{array}{l}
y_{1} \\
y_{2} \\
y_{3} \\
y_{4} \\
y_{5} \\
y_{6} \\
y_{7} \\
y_{8}
\end{array}\right]=\left[\begin{array}{l}
b_{0} \\
b_{1} \\
b_{2} \\
b_{3}
\end{array}\right] .}
\end{aligned}
$$

The values of the regression coefficients should be substituted to equation of the mathematical model in this way:

$$
y=b_{0}+b_{1}\left(\frac{x_{1}-x_{10}}{\Delta x_{1}}\right)+b_{2}\left(\frac{x_{2}-x_{20}}{\Delta x_{2}}\right)+b_{3}\left(\frac{x_{3}-x_{30}}{\Delta x_{3}}\right)
$$

The material applied for surface cladding experiment was base material of type S235JR. The thickness of deposited steel plate was $10 \mathrm{~mm}$, where surfacing clad was covered using the MAG semi-automatic process (see Fig. 1-2).

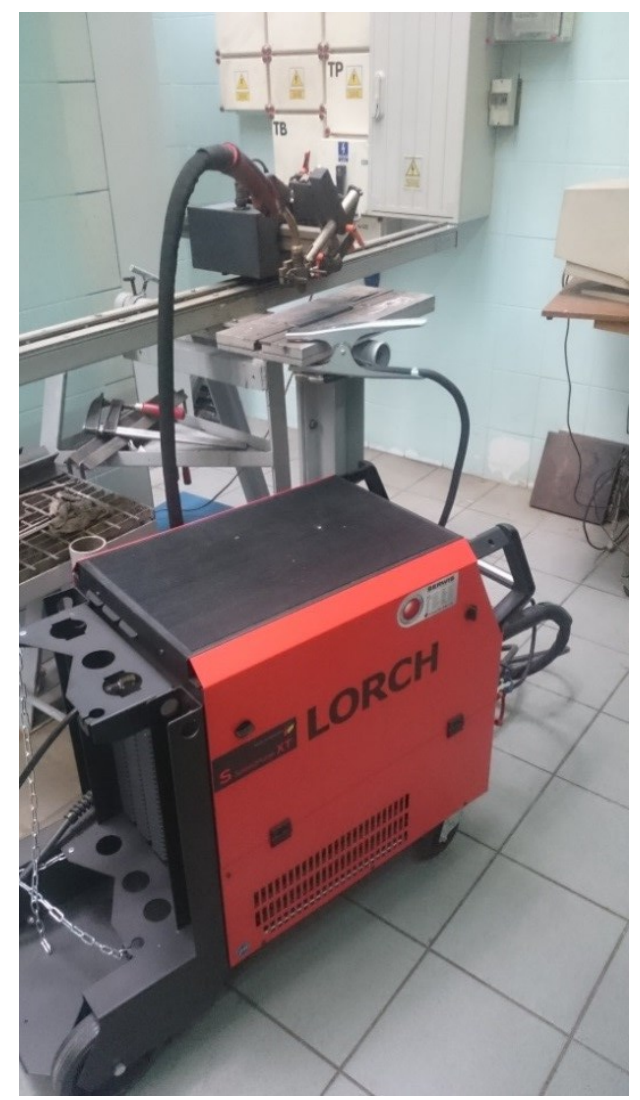

Fig. 1. The view position of work place 


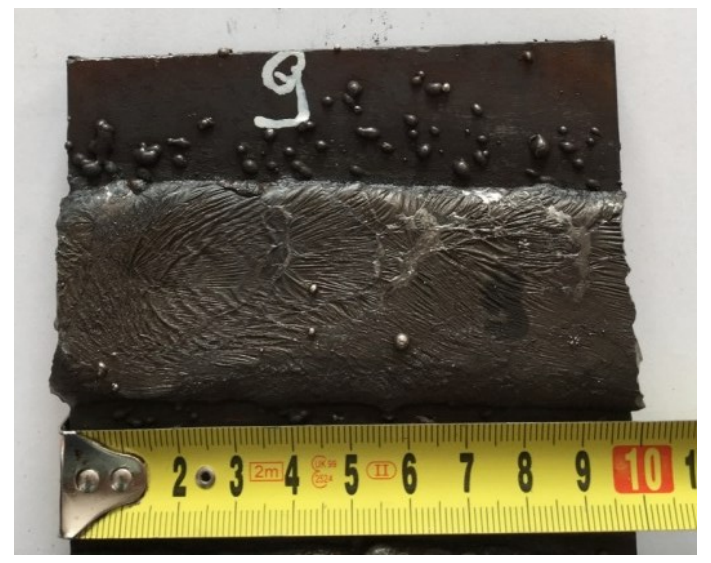

Fig. 2. Clad surfacing

The liquid weld pool was protected by the gas mixture M21 and cored wire Most F-64 with a diameter of $1.2 \mathrm{~mm}$ was used. Chemical composition specified by the manufacturer of this cored wire in Table 2 was presented. The used wire allows to obtain hard martensitic microstructure with carbides.

Table 2. Chemical composition of cored wire Most F-64

\begin{tabular}{ccccc}
\hline $\mathrm{C}$ & $\mathrm{Cr}$ & $\mathrm{V}$ & $\mathrm{W}$ & $\mathrm{Fe}$ \\
\hline 3.8 & 22.0 & 0.8 & 0.8 & rest \\
\hline
\end{tabular}

The surfacing weld is presented in Fig. 2. Direct current source with the welding current in the range of 213-277 A and the voltage in the range of 30-42 V was used in this experiment. Samples was made using experiment plan (Table 1). Then the samples were subject to the necessary visual testing and to the destructive testing in the scope of macroscopic, microscopic and hardness testing. For further mathematical analysis, hardness distribution studies were used. Hardness test was conducted in transverse direction. Fig. 3. shows the method of measuring the hardness distribution from the surface of the weld face.

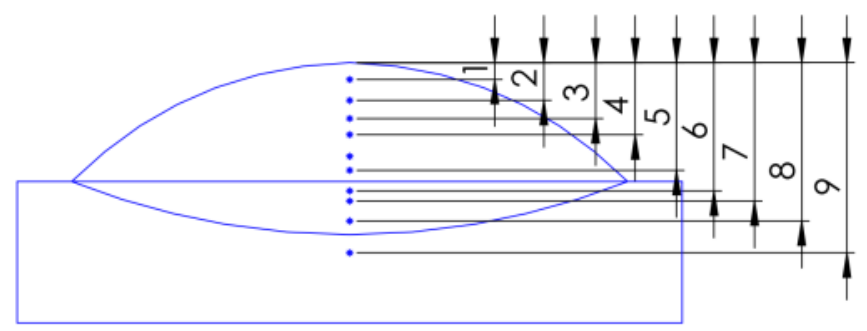

Fig. 3. Method of measuring the hardness distribution from the surface of the weld face

In basis of received results for average hardness for each specimen, applying the procedures in point 2 , the mathematical model was build.

\section{Results and discussion}

The planned parameters and the actual parameters that were read from the welding source are presented in Table 3. 
Table 3. Planned and actual parameters

\begin{tabular}{cccccccc}
\hline & \multicolumn{3}{c}{ Planned parameters } & \multicolumn{4}{c}{ Actual parameters } \\
\cline { 2 - 8 } & $\begin{array}{r}L_{e} \\
{[\mathrm{~mm}]}\end{array}$ & $\begin{array}{c}I \\
{[\mathrm{~A}]}\end{array}$ & $\begin{array}{c}V_{s} \\
{[\mathrm{~cm} / \mathrm{min}]}\end{array}$ & $\begin{array}{r}L_{e} \\
{[\mathrm{~mm}]}\end{array}$ & $\begin{array}{c}I \\
{[\mathrm{~A}]}\end{array}$ & $\begin{array}{c}V_{s} \\
{[\mathrm{~cm} / \mathrm{min}]}\end{array}$ & $U[\mathrm{~V}]$ \\
\hline 1 & 20 & 213 & 5 & 20 & 217 & 5 & 32.9 \\
2 & 30 & 213 & 5 & 30 & 217 & 5 & 36.6 \\
3 & 20 & 277 & 5 & 20 & 277 & 5 & 34.9 \\
4 & 30 & 277 & 5 & 30 & 267 & 5 & 40 \\
5 & 20 & 213 & 11 & 20 & 208 & 11 & 30.1 \\
6 & 30 & 213 & 11 & 30 & 218 & 11 & 36.5 \\
7 & 20 & 277 & 11 & 20 & 259 & 11 & 33.7 \\
8 & 30 & 277 & 11 & 30 & 260 & 11 & 42.1 \\
\hline
\end{tabular}

After visual testing, defects on the surface welding, such as spatters on the surface, were found (Fig. 2). The macroscopic testing showed micro cracks in cladding in transverse direction (Fig. 4).

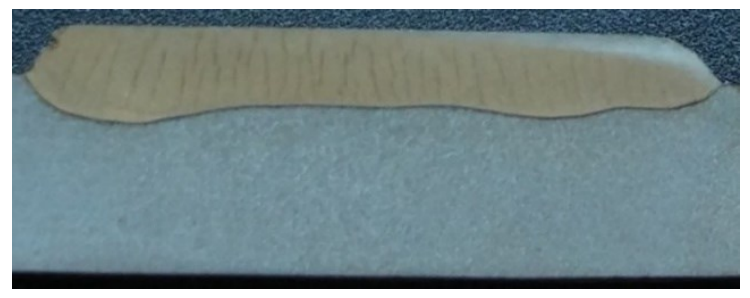

Fig. 4. Micro cracks in cladding [10]

An example of a hardness distribution in the transverse direction is shown on Fig. 5.

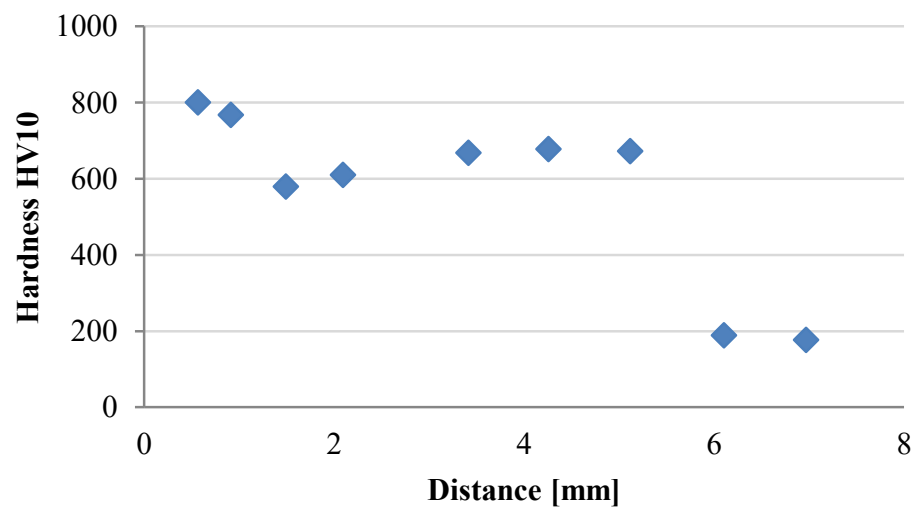

Fig. 5. Hardness distribution in the transverse direction in sample $3\left(L_{e}=20 \mathrm{~mm} ; I=277 \mathrm{~A}\right.$; $\left.V_{s}=5 \mathrm{~cm} / \mathrm{min}\right)[10]$

The highest average hardness achieved in sample $3\left(L_{e}=20 \mathrm{~mm} ; I=277 \mathrm{~A}\right.$; $\left.V_{s}=5 \mathrm{~cm} / \mathrm{min}\right)$. The lowest average hardness achieved in sample $5\left(L_{e}=30 \mathrm{~mm} ; I=213 \mathrm{~A}\right.$; $V_{s}=11 \mathrm{~cm} / \mathrm{min}$ ).

According to experimental procedure the regression coefficients $\left(b_{0}, b_{1}, b_{2}, b_{3}\right)$ were calculated. The equation (6), which was based on the (4), shows the example of calculation method regression coefficient : 


$$
\begin{aligned}
b_{1}=\frac{1}{8}[(-1) * & 562,07+(+1) * 654,39+(-1) * 682,06+(+1) * 595,37 \\
& +(-1) * 521,72+(+1) * 570,68+(-1) * 554,16+(+1) \\
& * 663,38]=20,47609
\end{aligned}
$$

After substituted the values of the regression coefficients to equation (5), mathematical model was obtained (7):

$$
y=H V 10=600,477+20,47609 x_{1}^{\circ}+23,26475 x_{2}{ }_{2}-22,9933 x_{3}^{\circ}
$$

Then the encoded variable, according to equation (7), were decoding. The mathematical model was received (8):

$$
y=H V 10=600,477+20,47609\left(\frac{L e-25}{5}\right)+23,26475\left(\frac{I-245}{32}\right)-22,9933\left(\frac{V_{s}-8}{3}\right)
$$

Fig. 6 shows comparison average hardness in claddings which was received in experiment to average hardness in claddings which was obtained from mathematical model.

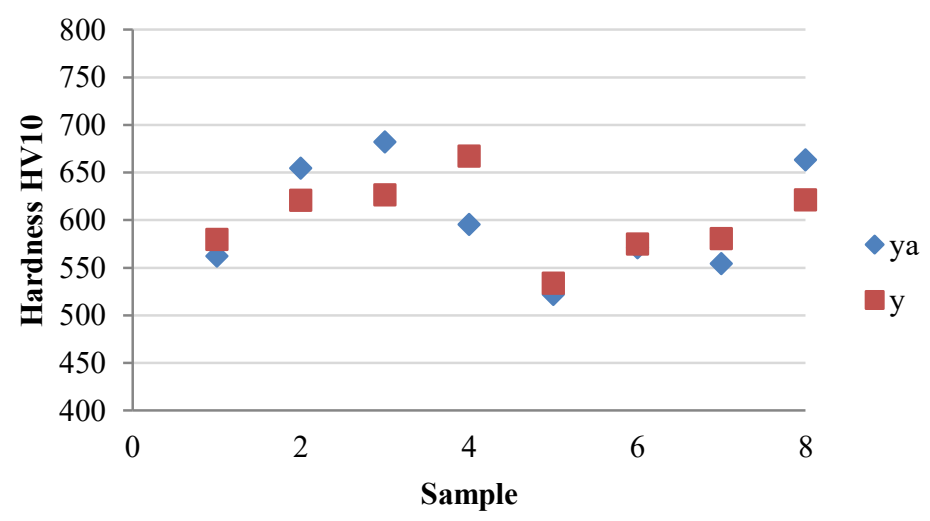

Fig. 6. Comparison actual value to value obtained from mathematical model [10]; $y a-$ actual value average hardness, $y$ - average value hardness obtained from mathematical model

Then relative error was calculated (Table 4). Relative error ranged from 0.7 to $12.07 \%$.

Table 4. Relative error of average hardness between actual value and value obtained from mathematical model [10]

\begin{tabular}{ccccc}
\hline $\mathbf{N}$ & $\boldsymbol{L}_{\boldsymbol{e}}[\mathbf{m m}]$ & $\boldsymbol{I}[\mathbf{A}]$ & $\begin{array}{c}\boldsymbol{V}_{\boldsymbol{s}} \\
{[\mathbf{c m} / \mathbf{m i n}]}\end{array}$ & $\begin{array}{c}\text { Relative } \\
\text { error [\%] }\end{array}$ \\
\hline 1 & 20 & 213 & 5 & 3.14 \\
2 & 30 & 213 & 5 & 5.15 \\
3 & 20 & 277 & 5 & 8.18 \\
4 & 30 & 277 & 5 & 12.07 \\
5 & 20 & 213 & 11 & 2.30 \\
6 & 30 & 213 & 11 & 0.70 \\
7 & 20 & 277 & 11 & 4.71 \\
8 & 30 & 277 & 11 & 6.35 \\
\hline
\end{tabular}


The final stage was microscope tests. The microscope tests provide a view of structures obtained during surface welding (Fig. 7). Fig. 7a show the distribution of chrominum and niob carbides in the clad. Fig. $7 \mathrm{~b}$ shows general view of structure near to fusion line. The distribution of crack on the clad layer (Fig.7c) is showed.
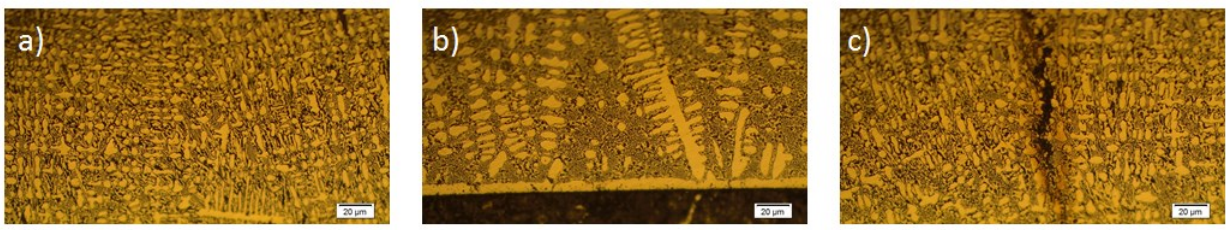

Fig. 7. The structures of surfacing welds, a) cladding, b) line of fusion, c) cladding with crack

\section{Conclusions}

Using the $2 \mathrm{k}$ experiment scheme, one can precisely determine the impact of the factors on the end properties. It also allows to build a mathematical model described by the linear equation. The built-in model describing the average hardness of the drink does not suffer from large errors. All regression coefficients (except for $b_{0}=600.477$ ) are at a similar level. Hardness increases as the length of the free wire increases and the welding intensity increases. The de-crease in hardness is due to the increase in the surfacing speed.

The purpose of building a mathematical model was to optimize the cladding process with use flux cored arc welding (FCAW) for MOST F64 wire applications.

\section{References}

1. R. Bęczkowski, Influence of cladding parameters with FCAW on bead geometry with Plackett-Burman experiment used, Arch. Metall. Mater. 63 (2), 681-687 (2018)

2. P. Kordas, Application of cored wires for production slide plates in the mining industry, M.Sc. Thesis. Częstochowa University of Technology (2017)

3. I. Pernis, J. Kasala, D. Žabecká, Resistance of weld clads made by flux-cored arc welding technology against erosive wear. Metalurgija 52 (3), 352-354 (2013)

4. IA. Riabcev, R. Rosert, IK. Senczenkov, E. Turyk, Welding Imperfections in Surfaced Layers. Biuletyn Instytutu Spawalnictwa 61 (3), 17-28 (2017)

5. K. Makles, M. Gucwa, The influence of the characteristics of welding arc on the properties of the padding welds. Welding Technology Review 89 (4), 10-14 (2017)

6. RP. Rauta, SF. Rodrigues, VS. Leal, GS. Reis, JrC. Aranas, CA. Ferraresi, Influence of Pushing and Pulling the Electrode Procedure and Addition of Second Layer of Welding on the Wear in Hardfacing of Fe-Cr-C. Materials Research 19 (5), 1193-1200 (2016)

7. M. Gucwa, R. Bęczkowski, The Effect of Heat Input on the Geometric Properties of Welded Joints, Archives of Foundry Engineering, 14(1), 127-130 (2014)

8. A. Babynets, I. Ryabtsev, A. Panfilov, V. Peremitko, Effect of Powder Surfacing on the Geometry of Run Surfaced on Flat and Cylindrical Elements. Biuletyn Instytutu Spawalnictwa 61 (6), 15-20 (2017)

9. ISO 6520-1:2009, Classification of geometric imperfections in metallic materials. Part 1: Fusion welding

10. R. Bęczkowski: Repair Welding of the Massive Cast. Archives of Foundry Engineering 17 (2), 5-8 (2017) 
11. ISO 5817-2014, Fusion-welded joints in steel, nickel, titanium and their alloys. Quality levels for imperfections

12. W. Orłowicz, V. Shevelya, A. Trytek, V. Kirilkov, Effect of the concentrated heat flow treatment on the structure and the antiwear properties of cast iron. Archives of Foundry Engineering 9 (2), 185-188 (2009)

13. W. Orłowicz, A. Trytek, Friction wear cast iron casting surface hardened by concentrated source of heat. Archives of Foundry Engineering 9 (2), 189-192 (2009)

14. T. Chmielewski, D. Golański, The role of welding in the remanufacturing process. Welding International 29 (11), 861-864 (2015).

15. M. Bober, J. Senkara, Comparative tests of plasma-surfaced nickel layers with chromium and titanium carbides. Welding International 30 (2), 107-111 (2016).

16. R. Chotěborský, M. Navrátilová, P. Hrabě, Effects of MIG process parameters on the geometry and dilution of the bead in the automatic surfacing. Research in Agricultural Engineering 57 (2), 56-62 (2011)

17. R. Chotěborský, P. Hrabě, M. Müller, J. Savková, M. Jirka, Abrasive wear of high chromium Fe-Cr-C hardfacing alloys. Research in Agricultural Engineering 54 (4), 192 198 (2008)

18. R. Chotěborský, P. Hrabě, A. Kabutey, Change of mechanical properties in substrate during rewelding deposit. Research in Agricultural Engineering 57 (3), 105-109 (2011)

19. R. Chotěborský, P. Hrabě, Effect of destabilization treatment on microstructure, hardness and abrasive wear of high chromium hardfacing. Research in Agricultural Engineering 59 (4), 128-135 (2013)

20. Bęczkowski, J. Cebulski, D. Pasek, M. Gucwa, Producing a layer of iron $\mathrm{Fe}-\mathrm{Cr}-\mathrm{C}-\mathrm{Nb}$ under conditions of intense heat reception, Engineering Mechanics 2017, 126-130 (2017) 